\title{
BMJ Open Study protocol: epidemiological and clinical characteristics of acute viral hepatitis in Brazilian health services
}

\author{
Roberta Sitnik (D) , ${ }^{1}$ Maira Marranghello Maluf, ${ }^{1}$ Ketti G Oliveira (D) , \\ Ricardo Andreotti Siqueira, ${ }^{1}$ Carlos Eduardo dos Santos Ferreira, ${ }^{1}$ \\ Cristóvão Luis Pitangueira Mangueira, ${ }^{1}$ Raymundo Soares Azevedo (1) ,2 \\ Maria Lucia Cardoso Gomes Ferraz, ${ }^{3}$ Maria Cassia Jacintho Mendes Correa, ${ }^{4}$ \\ Paulo Roberto Abrão Ferreira, ${ }^{5}$ Gerson Fernando Mendes Pereira, ${ }^{6}$ \\ Flávia Moreno Alves de Souza, ${ }^{6}$ Cristina Pimenta, ${ }^{6}$ João Renato Rebello Pinho ${ }^{1,7}$
}

To cite: Sitnik R, Maluf MM, Oliveira KG, et al. Study protocol: epidemiological and clinical characteristics of acute viral hepatitis in Brazilian health services. BMJ Open 2021;11:e045852. doi:10.1136/ bmjopen-2020-045852

- Prepublication history for this paper is available online. To view these files, please visit the journal online (http://dx.doi org/10.1136/bmjopen-2020045852).

Received 14 0ctober 2020 Accepted 23 June 2021

Check for updates

(c) Author(s) (or their employer(s)) 2021. Re-use permitted under CC BY-NC. No commercial re-use. See rights and permissions. Published by BMJ.

For numbered affiliations see end of article.

Correspondence to Dr João Renato Rebello Pinho; joao.pinho@einstein.br

\section{ABSTRACT}

Introduction Acute viral hepatitis is a disease of great clinical importance. This study proposes actions to better characterise cases of acute hepatitis in Brazil and to provide relevant information to institutionalised health policies within the Unified Health System. Available data on acute hepatitis in Brazil need to be re-evaluated regarding the different hepatotropic agent (hepatitis $A$ to $E$ virus) frequencies, as well as other agents that can cause similar clinical conditions, such as Herpes Simplex Virus 1 and 2(HSV1, HSV2), Varicella Zoster Virus (VZV), Cytomegalovirus (CMV), Epstein Barr Virus (EBV), Human Herpes Virus 6 and 7 (HHV6, HHV7), arbovirus (yellow fever, dengue, chikungunya, Zika), parvovirus B19, adenovirus, parechovirus, enterovirus, HIV, leptospirosis, toxoplasmosis and syphilis, in addition to autoimmune hepatitis. In this context, the primary aim of this study is the clinical-epidemiological and molecular characterisation of acute viral hepatitis in Brazilian health services from all geographical regions of the country. The present article describes the study protocol.

Methods and analysis This study will evaluate 2280 patients with symptoms and/or signs suggestive of acute liver disease in Brazilian health institutions in all five geographic Brazilian regions. Demographic, epidemiological and clinical data will be collected, as well as blood samples to be analysed at Hospital Israelita Albert Einstein Clinical Laboratory.

Ethics and dissemination Ethics approval was obtained at the national research ethics committee (Conselho Nacional de Ética em Pesquisa - CONEP-CAAE 00952818.4.1001.0071) and at all participating sites. Results will be published in journals and presented at scientific meetings.

\section{INTRODUCTION}

Acute hepatitis is caused by different aetiological agents and is characterised by the presence of inflammatory liver reactions. ${ }^{1-3}$ Among the infectious aetiological agents are viruses, bacteria, fungi, parasites and other non-infectious aetiologies, such as drug

\section{Strengths and limitations of this study}

- It represents states from all Brazilian regions.

- Participant states were defined jointly between the project management committee and the Department of Chronic Conditions Diseases and Sexually Transmitted Infections/Secretariat for Health Surveillance/Ministry of Health (DCCI/SVS/ MS), Brasília, Brazil, based on statistics available in previous epidemiological bulletins.

- Each centre was indicated by state's coordination, following predefined criteria for the smooth progress of the project.

- Some states and capitals were not included in the study, but findings from chosen participants will enable to draw an overview of acute hepatitis main causes in Brazil.

toxicity, metabolic alterations, autoimmune and hereditary diseases. Acute hepatitis is generally benign, but may progress to fulminant hepatitis. Some of them, depending on their aetiologies, may evolve to chronic hepatitis, to liver cirrhosis or even to hepatocellular carcinoma, representing a serious public health problem.

In Brazil, most frequent acute hepatitis are those of viral aetiology. ${ }^{4-7}$ Currently, five viruses of clinical importance, hepatitis A virus (HAV), hepatitis B virus (HBV), hepatitis C virus (HCV), hepatitis Delta virus (HDV) and hepatitis E virus (HEV), are described. ${ }^{8}$ Except for HBV, which has a DNA genome, all others are RNA viruses and differ in their routes of transmission and clinical presentation. Despite differences in viral genome type, molecular structure and taxonomic classification, these five aetiological agents have the liver as the main target. Clinical conditions vary from oligo or 
asymptomatic forms with a slight increase of liver transaminases to symptomatic forms with severe manifestations, such as acute liver failure. ${ }^{9}$ These viruses represent an important and growing public health problem. Every year 1.4 million people die from viral hepatitis-related cirrhosis and liver cancer. ${ }^{10}$ These numbers are extremely relevant, since the disease's distribution is universal and reaches several portions of population, causing a great impact of morbidity and mortality in health systems such as the Brazilian Unified Health System (SUS). ${ }^{211-15}$

In this context, in 2016, the WHO published its strategy with the aim of eliminating viral hepatitis as a threat to public health until $2030 .^{16}$ The objectives of this plan include reducing significantly the occurrence of new cases of hepatitis and mortality associated with hepatitis $\mathrm{B}$ and $\mathrm{C}$ mainly. ${ }^{2}$ Thus, this study aims to diagnose acute liver disease by serological markers and molecular tests in Brazilian services, not only in consequence to the most related five viruses associated with them, but also any other aetiological causes, to evaluate potential interventional measures that could be early implemented.

\section{Objectives}

Main objective

Clinical-epidemiological and molecular characterisation of acute viral hepatitis in Brazilian health services from all geographical regions of the country.

\section{Specific objectives}

- Determine the incidence rates of viral hepatitis and their genotypes in the studied services.

- Identify hepatitis caused by non-primarily hepatotropic agents, considering the prevalence of each region.

- Analyse epidemiological and sociodemographic profiles involved in the transmission of hepatotropic identified agents.

- Compare frequencies of different aetiologies among patients coinfected or not with HIV.

\section{METHODS AND ANALYSIS \\ Study design}

This is an observational, prospective and multicentric study that will evaluate consecutive patients with clinical signs suggestive of acute liver disease in Brazilian health institutions from different states from all regions of the country.

Participating centres will be selected by each state coordination, according to the following criteria: specialised professionals, at least 2000 patients per month, a laboratory collection structure including a centrifuge and a freezer at $-20^{\circ} \mathrm{C}$, internet access and available to follow-up and offer treatment for patients.

Demographic, epidemiological and clinical data will be collected at participating centres, as well as blood samples to be analysed at Hospital Israelita Albert Einstein Clinical Laboratory in São Paulo.

\section{Study population}

All patients over 18 years old characterised as suspected cases of acute hepatitis and treated in participating centres will be included in the study until the target of 2280 patients is achieved, if they sign the free and informed consent form. The project is expected to finish until the end of 2023.

\section{Sample size}

According to the 2020 Epidemiological Bulletin of the Health Surveillance Secretariat of the Ministry of Health, ${ }^{17}$ 37771 new cases of viral hepatitis were confirmed throughout Brazil in 2019. Of this total, approximately $2 \%$ were cases of hepatitis A, $37 \%$ cases of hepatitis B, $60 \%$ cases of hepatitis C and $0.4 \%$ cases of hepatitis Delta. From the information of proportion of occurrence $(p)$ of different types of hepatitis, it is possible to calculate the minimum sample $(n)$ for each proportion, with an error of $2 \%(e)$ and a $95 \%$ CI $(z)$, applying the formula below ${ }^{18}$ :

$$
n=z^{2}(p(1-p)) / e^{2}
$$

The minimum sample size calculated was 2272 cases, around $6 \%$ of the total cases observed in 2019. Sample size to fulfil the objectives for this protocol was rounded up to 2280 patients, treated consecutively in the participant centres.

The distribution of the total number visits per Brazilian region will be made according to the proportion of cases that each region contributed during the year indicated above. Thus, it is expected to represent the occurrence of hepatitis by geographical region starting from a consecutive sample of visits over the course of a year.

Table 1 indicates the proportion of cases from each Brazilian region in 2019, which was applied to the total of 2280 patients expected to compose the study sample to be collected in each centre.

To reach the final goal, each Brazilian region will have its monthly inclusion target, dividing the total number of samples by the number of months remaining for the end of the study.

\section{Eligibility criteria}

To be included in the study, the patient must fit one of these three eligibility criteria:

Table 1 Distribution of cases and minimum sample size by Brazilian region

\begin{tabular}{llll}
\hline Region & $\begin{array}{l}\text { Hepatitis } \\
\text { cases 2019 }\end{array}$ & $\begin{array}{l}\text { Proportion per } \\
\text { region }\end{array}$ & $\begin{array}{l}\text { Minimum } \\
\text { sample }\end{array}$ \\
\hline North & 3801 & 0.100633 & 229 \\
Northeast & 4004 & 0.106007 & 242 \\
Southeast & 16016 & 0.424029 & 967 \\
South & 11851 & 0.313759 & 715 \\
Center-West & 2099 & 0.055572 & 127 \\
Total & 37771 & & $\mathbf{2 2 8 0}$ \\
\hline
\end{tabular}


- Jaundiced symptomatic: Developed sudden jaundice less than 30 days prior to the study, with or without symptoms such as fever, malaise, nausea, vomiting, myalgia, coluria and faecal acolia. In laboratory investigation, the patient must present an increased value of aminotransferases (greater than or equal to five times the normal upper limit).

- Anicteric symptomatic: Individual without jaundice, who presents one or more symptoms such as fever, malaise, nausea, vomiting, myalgia and, in the laboratory investigation, presents an increased value of aminotransferases (greater than or equal to five times the normal upper limit).

- Asymptomatic anicteric: Individual without jaundice and without symptoms that suggest acute hepatitis, but with a sudden increase of aminotransferases (greater than or equal to five times the normal upper limit).

A specialised professional linked to the participating centre will include these cases.

Patients will be excluded from the study if they are younger than 18 years or if they refuse to sign the informed consent.

\section{Recruitment and collection}

The first step after each centre's ethical committee approves the study is a presential training provided by the study team to explain the workflow and activities to all participants. For this, a training manual was written and a website was developed with all the resources needed for the study (http://hepatitesvirais.com).

All eligible patients will be invited to participate in the study. If they accept the invitation and sign the informed consent form, they should answer a questionnaire and proceed to blood collection. All necessary documents, as well as collection material, are included in the collection kits that each participating centre will receive after training.

The study-specific questionnaire, which contains demographic, epidemiological and clinical data, must be completed digitally, using REDCap electronic system ${ }^{19} 20$ on a tablet provided by the study. The same platform will be used for study process control.

Next, six tubes of venous blood must be collected and properly identified with sequential labels provided by the study. After collection, samples must be centrifuged $(10 \mathrm{~min}$ at $4000 \mathrm{rpm})$ and frozen at -20 or $-80^{\circ} \mathrm{C}$. Frozen samples and completed documents will be collected in each centre following biosafety standards at least once a week by a contracted specialised carrier and sent for analysis in the Clinical Laboratory of Hospital Israelita Albert Einstein in São Paulo.

During all study period, there should be intense contact between the study team and participating centres for doubts clarification and samples logistics optimisation.

\section{Specimen processing}

On arrival at Albert Einstein laboratory in São Paulo, all samples will be handled according to biosafety standards such as the usual laboratory routine.

The study protocol includes biochemical tests (transaminases, alkaline phosphatase, total bilirubin and fractions, and gamma glutamyl transferase), and detection of viral hepatitis A, B, C, E and HIV by serology and molecular techniques. Only cases of positive hepatitis B will be tested for hepatitis D. Moreover, other tests (serological and molecular) will be carried out for diagnoses of arboviruses (yellow fever, dengue, Zika, chikungunya), viral infections (Herpes Simplex Virus 1 and 2(HSV1, HSV2), Varicella Zoster Virus (VZV), Cytomegalovirus (CMV), Epstein Barr Virus (EBV), Human Herpes Virus 6 and 7 (HHV6, HHV7), Parvovirus B19, Adenovirus, Parechovirus, Enterovirus), toxoplasmosis, leptospirosis, syphilis, autoimmune hepatitis (anti nuclear antibodies (ANA), liver kidney microsome antibody (anti-LKM) and antismooth muscle) and ceruloplasmin dosage (for Wilson's disease investigation). In cases where hepatitis A-E virus nucleic acids are detected, the sequencing of genetic material will be performed for genotypes and subgenotypes characterisation. These sequences will be used for phylogenetic analyses together with public sequences obtained from the international repository of biological sequences GenBank NCBI in the NCBI and other ones, depending on the infectious agent found.

In endemic areas for malaria, the participating centres must perform their usual test for malaria detection and send the result to the study team. Regardless of the results, the patient will be included in the study.

The methods for each test are described in tables 2-4.

\section{Results reporting}

Test reports will be available at Hospital Israelita Albert Einstein's Laboratory information system. Each centre will be able to access their patients' results with a specific password for this purpose.

Patients will be instructed to return to the participating centre where collection was performed to obtain their results. At that time, all cases that require medical assistance should be guided in terms of treatment and follow-up, according to the usual protocol of each centre. Also, participating patients will receive an amount of $\mathrm{R} \$ 35.00$ (equivalent to approximately $\$ 6.50$ considering February 2021 quotation), in the form of a prepaid card, as a reimbursement for any expenses they may have due to the study.

Patients who do not return and have a positive result will be actively contacted by the respective centre within 10 days from result.

\section{Monitoring and quality control}

To ensure the reliability and quality of the study data, tools were developed to assure the correct execution of the project. Actions were planned before data collection begins, with extensive bibliographic research, transport 
Table 2 Kits used for biochemical testing

\begin{tabular}{ll}
\hline Exams & Biochemical kits \\
\hline GGT & $\begin{array}{l}\text { Kit ROCHE: GGT ( } \gamma \text {-glutamyltransferase ver.2 standardised against IFCC/Szasz) } \\
\text { Enzymatic colorimetric assay }\end{array}$ \\
ALT & KIT ROCHE: ALTL (alanine aminotransferase acc. to IFCC no phosphate activation) \\
AST & KIT ROCHE: ASTL (aspartate aminotransferase acc. IFCC without pyridoxal phosphate activation) \\
Alkaline phosphatase & KIT ROCHE: ALKP (alkaline phosphatase)-Colorimetric assay \\
Total bilirubin & KIT ROCHE: BILT3 (bilirubin total version 3)-Diazo colorimetric method \\
Direct and indirect bilirubin & KIT ROCHE: BILD2 (bilirubin direct version 2)-Diazo method \\
\hline
\end{tabular}

logistics preparation, questionnaire creation on REDcap platform, operating manuals development (for interviews, sample collection and samples logistics) and training.

A mock study was performed to identify and correct problems in data collection, sample transportation, procedures and instruments. All health professionals involved in the research are trained and certified by the study team.

Data and specimen collection will be periodically evaluated by the study team, in order to generate reports,

Table 3 Kits used for immunological testing

Exam/Disease Immunological tests

Hepatitis A

Kit HAVAb-IgM and IgG-Architect (Abbott), chemiluminescence

Hepatitis B Kit HBsAg Qualitative II-Architect (Abbott), chemiluminescence Kit Anti-HBc Total-Architect (Abbott), chemiluminescence Kit Anti-HBc IgM-Architect (Abbott), chemiluminescence

Hepatitis C Kit Anti-HCV - Architect (Abbott), chemiluminescence

Hepatitis D Kit LIAISON XL MUREX Anti-HDV, chemiluminescence

Hepatitis E Kit HEV IgG/HEV IgM - RecomWell HEV (Mikrogen GmbH), ELISA

HIV Kit HIV Ag/Ab Combo, Architect, Abbott

Yellow fever Kit Anti-Yellow Fever Virus IIFT IGG/Anti-Yellow Fever Virus IIFT IGM (Euroimmun), indirect immunofluorescence

Dengue fever Kit Panbio Dengue IgG Indirect Elisa/Panbio Dengue IgM Capture Elisa Panbio, Elisa

Chikungunya Kit Euroimmun IgM/lgG (Medical-laboratory diagnosis Brazil), Elisa

Zika Kit Euroimmun IgM/lgG (Medical-laboratory diagnosis Brazil), Elisa

Cytomegalovirus Kit Cytomegalovirus (CMV) IgM/ CMV IgG (Abbott), chemiluminescence

Epstein-Barr virus Kit Epstein Barr Virus (EBV) Viral Capsid Antigen VCA-M, EBV VCA-G e EBV Epstein-Barr Nuclear Antigen EBNA-G (Abbott), chemiluminescence

Toxoplasmosis Kit Toxo IgG e Toxo IgM (Abbott), chemiluminescence

Herpes I and II Herpes simplex 1+2 Virclia IgG/lgM, chemiluminescence

Parvovirus B19 LIAISON Biotrin Parvovirus IgG/IgM, chemiluminescence

Varicella-zoster virus LIAISON VZV IgG/IgM, chemiluminescence

Leptospirosis External laboratory

Syphilis - Treponemal Kit: Syphilis (Abbott), chemiluminescence/Kit: Imuno-CON-FTA-Abs (Wama Diagnostics), indirect immunofluorescence

Syphilis - non- Kit VDRL (Wama Diagnostics), flocculation

treponemal

Ceruloplasmin Kit Siemens, nephelometry (BNII)

Autoimmune hepatitis Anti-muscle-smooth IgG, Elisa (Inova) and indirect immunofluorescence (Aesku) liver kidney microsome antibody Anti-LKM IgG, indirect immunofluorescence (Aesku) anti nuclear antibodies ANA, indirect immunofluorescence (Inova and Bion)

HCV, hepatitis C virus; Ig, immunoglobulin. 
Table 4 Kits used for molecular testing

\begin{tabular}{|c|c|}
\hline Exam/Disease & Molecular tests \\
\hline Hepatitis A & RealStar HAV RT-PCR Kit 1.0 Altona \\
\hline Hepatitis B & Viral load using the HBV CAP/CTM kit (Cobas AmpliPrep/Cobas TaqMan) v2.0, Roche Molecular Systems \\
\hline Hepatitis D & RealStar HDV RT-PCR Kit 1.0 Altona \\
\hline Hepatitis E & RealStar HEV RT-PCR Kit 2.0 Altona \\
\hline Genotyping HAV & Sequencing of HAV genome ${ }^{21}$ \\
\hline Genotyping HBV & Sequencing of HBV genome ${ }^{21}$ \\
\hline Genotyping HCV & Sequencing of HCV genome ${ }^{21}$ \\
\hline Genotyping HDV & Sequencing of HDV genome ${ }^{21}$ \\
\hline Genotyping HEV & Sequencing of HEV genome ${ }^{21}$ \\
\hline Dengue fever & Kit Simplexa Dengue (Focus Diagnostics/Medivax), real-time PCR \\
\hline Chikungunya & Tib molbiol kit (Roche), real-time PCR \\
\hline Zika virus & Real-time $\mathrm{PCR}^{23}$-in-house \\
\hline Cytomegalovirus & Kit Multiplex Neuro 9 (Mobius), real-time PCR/Kit XGEN MASTER CMV/EBV (Mobius), real-time PCR \\
\hline Epstein-Barr virus & Kit Multiplex Neuro 9 (Mobius), real-time PCR/Kit XGEN MASTER CMV/EBV (Mobius), real-time PCR \\
\hline Toxoplasmosis & Kit XGEN MASTER TOXO (Mobius), real-time PCR \\
\hline Herpes I and II & Kit Multiplex Neuro 9 (Mobius), real-time PCR \\
\hline Parvovirus B19 & Kit Multiplex Neuro 9 (Mobius), real-time PCR \\
\hline $\begin{array}{l}\text { Herpesvirus } 6 \\
\text { and } 7\end{array}$ & Kit Multiplex Neuro 9 (Mobius), real-time PCR \\
\hline
\end{tabular}

HAV, hepatitis A virus; HBV, hepatitis B virus; HCV, hepatitis C virus; HDV, hepatitis Delta virus; HEV, hepatitis E virus.

including information about valid included patients. Those reports will be distributed periodically to all people involved in the study.

Moreover, each centre will receive at least one in loco monitoring visit by the study team to evaluate protocol compliance and provide recertification.

Biological sample evaluation will be done during all transportation processes, which include checking time, temperature and other sample conditions.

\section{Data collection methods}

Clinical information and medical history will be obtained at enrolment directly from patients, their family members and/or medical charts. Laboratory tests results will be retrieved from medical charts and laboratory reports.

The following data will be collected: identification, age, gender, profession, place of residence, comorbidities, sexual orientation, sexual history information, symptoms, symptom time, recent trips, medicines in use, history of risk behaviour and exposition to drugs, alcohol or people with confirmed diagnosis of viral hepatitis.

All study variables will be collected and managed using REDCap electronic data capture tools ${ }^{19}$ hosted at Hospital Israelita Albert Einstein.

\section{Data management}

All electronic data collected in REDCap are available for the study team through password-secure unique usernames. Each participant has specific user rights inside REDCap profile according to their role in the study. Each centre has access only to their own patients.

The study team will perform an internal data monitoring for all included patients and audit the information input by participant centres. They will also complete the laboratory results in order to perform statistical analyses. 


\section{Statistical methods}

The set of data collected will be grouped by hepatitis aetiology to determine if there are differences between groups for variables of interest indicated in the interview and clinical examination, and for laboratory variables (univariate and bivariate analyses), with a significance level of $5 \%(\alpha=0.05)$.

The continuous quantitative variables will be compared by the average of values to verify the hypothesis of difference between the groups described above by parametric methods indicated for each interest situation (t-test for two independent samples, one-factor analysis of variance or Pearson's correlation).

Qualitative ordinal variables and discrete quantitative variables without Gaussian distribution will be analysed by non-parametric methods (Mann-Whitney-Wilcoxon test for two independent samples, Kruskal-Wallis test or Spearman correlation) to know if there is difference between groups studied.

Nominal qualitative variables will be tested for association with groups defined above using the $\chi^{2}$ test or Fisher's exact test when indicated.

From the univariate and bivariate analyses described above, the variables with a statistically significant association $(p<0.05)$ will be selected to compose the multinomial logistic analysis, whose objective is to identify the independent variables which contribute to predict a given hepatitis aetiology by OR estimation.

\section{Patient and public involvement}

No patient involved.

\section{DISCUSSION}

This is the first Brazilian nationwide study to determine acute hepatitis occurrence and the social, demographic and behavioural factors related to them. Critical analysis of the study results will contribute to epidemiological knowledge of the distribution of acute hepatitis across geographical regions and will establish a baseline to evaluate the main causes and the best approach in each region.

There are some limitations in this study. The sampling is not random. Brazil is a large country, and due to logistic reasons, the sampling is restricted to some selected states, and in each state to centres selected by the local government.

It is important to mention that the current Brazilian notification system has several limitations. Among them, we highlight the absence of notification of many cases and some inaccuracies related to the lack of specific aetiological diagnosis due to difficulties in accessing adequate laboratory tests in a large part of the Brazilian territory.

The path for the elimination of viral hepatitis as a public health problem in Brazil depends on knowledge of the impact of these diseases in the different regions, the accurate identification of new cases of these infections, the interruption of the chain of transmission of the disease and finally the institution of appropriate treatment for all infected patients.

With this study, we will be able to provide extremely relevant information to institutionalised health policies within SUS scope. The available data on acute hepatitis in Brazil need to be evaluated to know if there have been any recent changes in the epidemiological pattern regarding different hepatotropic agent frequencies, as well as other agents that can cause similar clinical conditions. These data will be of great importance to guide public policies for prevention and assistance in different locations in Brazil.

\section{Ethics and dissemination policy}

Each centre will be registered as a participant and sample collection will only begin after approval by both national ethics committees (CONEP-CAAE 00952818.4.1001.0071) and by each local ethical committee.

The participating health services nominated by state's coordination until now are listed below and ethical approval has been obtained at all listed participating sites:

Centro de Referência e Treinamento em DST/AIDS - São Paulo-SP.

Hospital das Clínicas de São Paulo/USP - São Paulo-SP.

Hospital São Paulo/UNIFESP - São Paulo-SP.

Instituto de Infectologia Emilio Ribas - São Paulo-SP.

Faculdade de Medicina do ABC/FMABC-FUABC Santo André-SP.

Hospital das Clínicas - Ribeirão Preto-SP.

Polo de Hepatites do IASERJ/UERJ - Rio de Janeiro-RJ.

Hospital Felício Rocho - Belo Horizonte-MG.

Centro de Pesquisa Clínica da Universidade Federal do Maranhão - São Luís-MA.

Hospital Universitário Professor Edgard Santos - Salvador-BA.

Hospital Universitário Júlio Muller - Cuiabá-MT.

Hospital-Dia Esterina Corsini/UFMG - Campo Grande-MS Fundação Santa Casa de Misericórdia do Pará - Belém-PA. Fundação de Medicina Tropical Dr. Heitor Vieira Dourado - Manaus-AM.

Centro de Medicina Tropical de Rondônia - Porto Velho-RO

Unidade de Saúde de Referência de Doenças Tropicais - Rio Branco-AC.

Hospital de Clínicas - Porto Alegre-RS.

Hospital Nereu Ramos - Florianópolis-SC.

Consórcio Intermunicipal de Saúde (CONIMS) - Pato Branco-PR.

The results from this study will be communicated to healthcare professionals, the public and other relevant groups via publication, reporting in results databases or other data-sharing arrangements as appropriate. Communication of results to participants will be done if direct benefit or prevention of harm is anticipated from disclosure of the study results.

Author affiliations

${ }^{1}$ Laboratório de Patologia Clínica e de Anatomia Patológica, Hospital Israelita Albert Einstein, Sao Paulo, Brazil 
${ }^{2}$ Department of Pathology, LIM01, Universidade de São Paulo Faculdade de Medicina, Sao Paulo, Brazil

${ }^{3}$ Gastroenterology Division, Universidade Federal de Sao Paulo, Sao Paulo, Brazil

${ }^{4}$ Department of Infectious and Parasitic Diseases, LIM52, Universidade de São Paulo Faculdade de Medicina, Sao Paulo, Brazil

${ }^{5}$ Infectology Division, Universidade Federal de São Paulo, Sao Paulo, São Paulo, Brazil

${ }^{6}$ Department of Chronic Conditions Diseases and Sexually Transmitted Infections, Secretariat for Health Surveillance, Ministry of Health of Brazil, Brasilia, Brazil ${ }^{7}$ Department of Pathology, LIM03 and Department of Gastroenterology, LIM07, Universidade de São Paulo Faculdade de Medicina, Sao Paulo, Brazil

Twitter João Renato Rebello Pinho @jrrpinho

Acknowledgements We are thankful to all participant centres and their respective coordinators.

Contributors RS, MMM, KG0, RAS, CFdSF, CLPM, RSA, MLCGF, FMAdS, PC and JRRP are the authors. RS, FM, CMCJM, FPRA, GFMP, dSFMA, PC and JRRP conceived the idea of the study and its design. MMM, KGO and RSA are essential to data collection. RS, MMM and KGO wrote the first draft of the manuscript. ARSA, GFMP, dSFMA, PC and JRRP provided advice and supervision. All authors met the criteria: (1) Substantial contributions to the conception or design of the work; or the acquisition, analysis or interpretation of data for the work. (2) Drafting the work or revising it critically for important intellectual content. (3) Final approval of the version to be published. (4) Agreement to be accountable for all aspects of the work in ensuring that questions related to the accuracy or integrity of any part of the work are appropriately investigated and resolved.

Funding This work is financed by Hospital Israelita Albert Einstein through the Program for Supporting the Institutional Development of the Public Health System (PROADI-SUS), supported by the Ministry of Health of Brazil.

Competing interests None declared.

Patient and public involvement Patients and/or the public were not involved in the design, or conduct, or reporting or dissemination plans of this research.

Patient consent for publication Not required.

Provenance and peer review Not commissioned; externally peer reviewed.

Open access This is an open access article distributed in accordance with the Creative Commons Attribution Non Commercial (CC BY-NC 4.0) license, which permits others to distribute, remix, adapt, build upon this work non-commercially, and license their derivative works on different terms, provided the original work is properly cited, appropriate credit is given, any changes made indicated, and the use is non-commercial. See: http://creativecommons.org/licenses/by-nc/4.0/.

\section{ORCID iDs}

Roberta Sitnik http://orcid.org/0000-0002-6243-8118

Ketti G Oliveira http://orcid.org/0000-0002-0593-4422

Raymundo Soares Azevedo http://orcid.org/0000-0003-0660-2371

\section{REFERENCES}

1 World Health Organization. Prevention and control of viral hepatitis infection: framework for global action. Geneva: WHO, 2012. http:// www.who.int/hepatitis/publications/Framework/en/
2 Brasil, Ministério da Saúde, Secretaria de Vigilância em Saúde, Departamento deDST, Aids e Hepatites Virais. Manual Técnico para O Diagnóstico das Hepatites Virais. Brasília: Ministério da Saúde, 2015.

3 Cacciola I, Scoglio R, Alibrandi A, et al. SIMG-Messina Grupo de Estudo para Hipertransaminasemia. Avaliação DOS níveis de enzimas hepáticas E identificação de pacientes com doença hepática assintomática $\mathrm{Na}$ atenção primária. Intern Emerg Med 2017;12:181-6.

4 Brasil, Ministério da Saúde. A B C D E das hepatites virais para agentes comunitários de saúde. Brasília: Ministério da Saúde, 2009.

5 Cardoso FS, Marcelino P, Bagulho L, et al. Acute liver failure: an upto-date approach. J Crit Care 2017;39:25-30.

6 Kwong S, Meyerson C, Zheng W, et al. Acute hepatitis and acute liver failure: pathologic diagnosis and differential diagnosis. Semin Diagn Pathol 2019;36:404-14.

7 Stravitz RT, Lee WM. Acute liver failure. Lancet 2019;394:869-81.

8 Louten J. Hepatitis viruses. Essential human virology. Chapter 12. Cambridge, Massachusetts: Academic Press, 2016.

9 Pauly MD, Kamili S, Hayden TM. Impact of nucleic acid extraction platforms on hepatitis virus genome detection. J Virol Methods 2019;273:113715.

10 Jefferies M, Rauff B, Rashid H, et al. Update on global epidemiology of viral hepatitis and preventive strategies. World J Clin Cases 2018;6:589-99.

11 Ferreira CT, Silveira TRda. Hepatites virais: aspectos dA epidemiologia E dA prevenção. Rev Bras Epidemiol 2004;7:473-87.

12 Ferreira AdeSP, Perez RdeM, Ferraz MLG, et al. Acute hepatitis C in Brazil: results of a national survey. J Med Virol 2011;83:1738-43.

13 Vieira MRM, Gomes LMX, Nascimento WDM, et al. ASPECTOS EPIDEMIOLÓGICOS DAS HEPATITES VIRAIS no NORTE de MINAS GERAIS. Rev. baiana de saúde pública 2010;34:348-58.

14 World Health Organization. Global hepatitis report 2017. Geneva: WHO, 2017. http://www.who.int/hepatitis/publications/globalhepatitis-report2017/en/

15 Brasil, Ministério da Saúde, Secretaria de Vigilância em Saúde. Coordenação-Geral de Desenvolvimento dA Epidemiologia em Serviços. Guia de Vigilância em Saúde. Brasília: Ministério da Saúde, 2017.

16 World Health Organization. Global health sector strategy on viral hepatitis 2016-2021. Geneva: WHO, 2016. http://www.who.int/ hepatitis/strategy2016-2021/ghss-hep/en/

17 Brasil, Ministério da Saúde, Secretaria de Vigilância em Saúde. Departamento de Doenças de Condições Crônicas E Infecções Sexualmente Transmissíveis (DCCl) Bol Epidem. 2020; Número especial; ISSN 9352-7864 2020.

18 Cochran WG. Sampling techniques. New York, NY: John Wiley \& Sons, 1977.

19 Harris PA, Taylor R, Thielke R, et al. Research electronic data capture (REDCap) - A metadata-driven methodology and workflow process for providing translational research informatics support. J Biomed Inform 2009;42:377-81.

20 Harris PA, Taylor R, Minor BL, et al. The REDCap Consortium: building an international community of software platform partners. $J$ Biomed Inform 2019;95:103208.

21 Greninger AL, Naccache SN, Federman S, et al. Rapid metagenomic identification of viral pathogens in clinical samples by real-time nanopore sequencing analysis. Genome Med 2015;7:99.

22 Domingo C, Patel P, Yillah J, et al. Advanced yellow fever virus genome detection in point-of-care facilities and reference laboratories. J Clin Microbiol 2012:50:4054-60.

23 Lanciotti RS, Kosoy OL, Laven JJ, et al. Genetic and serologic properties of Zika virus associated with an epidemic, YAP state, Micronesia, 2007. Emerg Infect Dis 2008;14:1232-9. 